\title{
The scientific and regulatory rationale for indication extrapolation: a case study based on the infliximab biosimilar CT-P13
}

\author{
Walter Reinisch, Edouard Louis \& Silvio Danese
}

To cite this article: Walter Reinisch, Edouard Louis \& Silvio Danese (2015) The scientific and regulatory rationale for indication extrapolation: a case study based on the infliximab biosimilar CT-P13, Expert Review of Gastroenterology \& Hepatology, 9:sup1, 17-26, DOI: 10.1586/17474124.2015.1091306

To link to this article: http://dx.doi.org/10.1586/17474124.2015.1091306

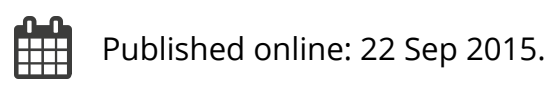

Submit your article to this journal $₫$

Џll Article views: 1805

Q View related articles $\longleftarrow$

View Crossmark data ¿

Citing articles: 12 View citing articles 


\section{EXPERT REVIEWS}

The scientific and regulatory rationale for indication extrapolation: a case study based on the infliximab biosimilar CT-P13

Expert Rev. Gastroenterol. Hepatol. 9(S1), S17-S26 (2015)

\section{Walter Reinisch ${ }^{1}$,} Edouard Louis ${ }^{2}$ and Silvio Danese ${ }^{3}$

${ }^{1}$ Division of Gastroenterology, Department of Medicine, McMaster University, Hamilton, Ontario, Canada ${ }^{2}$ Department of Gastroenterology, University Hospital CHU of Liege, Liege, Belgium

${ }^{3}$ Department of Gastroenterology, IBD Center, Humanitas Research Hospital, Rozzano, Milan, Italy

*Author for correspondence: reinisw@mcmaster.ca

Extrapolation of clinical data from other indications is an important concept in the development of biosimilars. This process depends on strict comparability exercises to establish similarity to the reference medicinal product. However, the extrapolation paradigm has prompted a fierce scientific debate. CT-P13 (Remsima ${ }^{\circledR}$, Inflectra ${ }^{\circledR}$ ), an infliximab biosimilar, is a TNF antagonist used to treat immune-mediated inflammatory diseases. On the basis of totality of similarity data, the EMA approved CT-P13 for all indications held by its reference medicinal product (Remicade ${ }^{\circledR}$ ) including inflammatory bowel disease. This article reviews the mechanisms of action of TNF antagonists in immune-mediated inflammatory diseases and illustrates the comparable profiles of CT-P13 and reference medicinal product on which the extrapolation of indications including inflammatory bowel disease is based.

KEYwORDS: biosimilar • CT-P13 • infliximab • extrapolation • inflammatory bowel disease • mechanism of action - pharmacokinetics

The extrapolation of safety and efficacy data from one clinical indication to another is a scientific principle that may be utilized in certain situations during biologic drug development. For a novel or 'originator' biologic, this concept may be applied when a major change in the manufacturing process is thought to have the potential to impact the clinical profile of the drug [1]. In most instances, where a change in the manufacturing process for an originator biologic has occurred, no clinical studies at all are required. However, when major changes that may have a clinical impact take place - and after it has been demonstrated that the nonclinical characteristics of the drug are sufficiently similar before and after the process change - it is usual for new clinical data to be collected in one indication and then 'extrapolated' to other indications held by the drug [1]. This extrapolation concept is, however, more commonly utilized during development of a similar biologic medicinal product (or 'biosimilar'). In this case, if similarity between a biosimilar and its originator drug (or 'reference medicinal product' [RMP]) is demonstrated in one indication, approval of the biosimilar in all indications held by the RMP may be granted. Such approval, however, requires the demonstration of comparability in quality, nonclinical and clinical data, as well as an evidence-based justification for extrapolation as outlined in biosimilar guidelines issued by the EMA [2]. This justification should include evidence that the mechanism(s) of action of the drug in question is the same in all indications involved in the extrapolation process. Despite the regulatory requirement to justify extrapolation, concerns have been expressed regarding the scientific validity of this approach, in particular whether it is appropriate to use a biosimilar in an indication in which the efficacy and safety of the biosimilar have not been formally evaluated [3-5].

CT-P13 (Remsima ${ }^{\circledR}$, Inflectra ${ }^{\circledR}$ ) is a biosimilar of infliximab, a human-murine chimeric monoclonal antibody (mAb) against TNF that 
is used in the treatment of various immune-mediated inflammatory diseases (IMIDs) [6]. CT-P13 was approved by the EMA in September 2013 for all indications held by the infliximab RMP (Remicade ${ }^{\circledR}$ ), namely rheumatoid arthritis (RA), ankylosing spondylitis (AS), psoriatic arthritis ( $\mathrm{PsA})$, psoriasis ( $\mathrm{PsO}$ ), adult and pediatric Crohn's Disease (CD) and adult and pediatric ulcerative colitis (UC) [7,8]. European approval for these indications was based on the acknowledgment that the main mechanism of action of infliximab in the different indications was the same and on data from a comprehensive nonclinical study program, which showed that all major physicochemical characteristics and biologic activities of CT-P13 and RMP were comparable $[8,9]$ plus two clinical trials in which RA or AS patients were treated with the biosimilar or the RMP $[10,11]$. Outside of Europe, Health Canada granted approval of CT-P13 for the treatment of RA, AS, PsA or PsO but not for inflammatory bowel disease (IBD; i.e., CD and UC) [12]. Such discrepancies in regulatory approaches add to the confusion surrounding the scientific validity of extrapolation in biosimilar development.

In this article, we use the example of CT-P13 as a means to explain the scientific and regulatory principles that underlie the rationale for extrapolation. We begin by considering the physicochemical characterization of two infliximab molecules and the role of TNF and TNF antagonists in the pathogenesis and treatment of IMIDs, as a means to explain the rationale for extrapolation of the clinical data for CT-P13 to IBD indications.

\section{Physicochemical characterization of CT-P13 \& RMP}

The physicochemical characteristics of CT-P13 and infliximab RMP have been compared using the current state-of-art technology [9]. Thorough comparability analysis showed that CTP13 possesses highly similar properties in terms of primary/ higher order structures and purity/impurity. Regarding charge isoforms, there are noticeable differences in the relative proportion of basic variants in CT-P13 and RMP. However, the amount of basic variants derived from C-terminal lysine was shown to have no effect on biological potency due to rapid clipping by carboxypeptidase $\mathrm{B}$ in vivo [9]. There are also numerical differences in fucosylation between CT-P13 and infliximab RMP. Consequently, and as discussed in detail below, CT-P13 has a lower binding affinity for FcyRIIIa than for RMP, with lower levels of antibody-dependent cellular cytotoxicity (ADCC) being observed with CT-P13 in an in vitro model using natural killer (NK) cells as effector cells and transmembrane TNF (tmTNF)-expressing Jurkat cells as target cells. However, as demonstrated in other models that are more representative of pathophysiological conditions (see below), differences in fucosylation and FcyRIIIa binding between CT-P13 and infliximab RMP are not likely to be clinically relevant $[8]$.

\section{TNF \& TNF antagonists in the pathogenesis \& treatment} of IMIDs: a brief overview

Despite their varying clinical presentation, IMIDs such as RA, AS, PsO, PsA and IBD share similar mechanisms of pathogenesis, most notable of which is the overexpression of TNF [13]. TNF is a proinflammatory cytokine with a well-characterized physiological profile [14]. It is produced by various immune and nonimmune cells including macrophages, T lymphocytes, neurons and keratinocytes. The stimulation of TNF-producing cells leads to the expression of tmTNF, which can be cleaved, releasing soluble TNF (sTNF). tmTNF and sTNF bind to TNF receptors (TNFRs) on the cell surface of TNF-responsive cells, initiating various intracellular signaling pathways, including those involved in the initiation of apoptosis and the regulation of genes involved in inflammation [14].

Evidence for the involvement of TNF in IBD also includes the greatly increased number of TNF-producing cells in the lamina propria of the bowel in IBD patients [15,16] and increased TNF concentrations in the stools of children with active IBD [17]. The central role of TNF overexpression in the pathogenesis of IMIDs is also reflected by the efficacy of various biologic drugs that inhibit its function. TNF antagonists approved for use in different IMID indications include infliximab, etanercept, adalimumab, certolizumab and golimumab [18]. All are TNF-specific mAbs, or fragments thereof, with the exception of etanercept, which is a fusion protein between the extracellular portions of TNFR2 and the Fc portion of human IgG1 [14]. Although inhibition of TNF is believed to be the common denominator underlying the therapeutic activity of these agents, different TNF-driven mechanisms of disease have been identified (see next section). While some of these mechanisms occur in numerous IMIDs, others may be unique to a single indication. Structural differences between TNF antagonists affect their ligand-binding characteristics, which in turn lead to some differences in the TNF mechanisms of action (MOAs) that are targeted by these agents [14]. In the following section, we consider the TNF biochemical pathways that may be important in IBD and review the studies that have compared the effects of CT-P13 and the infliximab RMP on these TNF MOAs.

\section{Targeting the possible MOAs of TNF in IBD: how do CT-P13 \& RMP compare? Binding \& neutralization of sTNF \& tmTNF}

The primary mechanism via which infliximab is thought to exert its therapeutic effect in IBD and other IMIDs is by binding to sTNF and tmTNF and thereby preventing TNFR binding and activation (Figure 1). Such neutralization of TNF activity leads to suppression of numerous proinflammatory processes including induction of other proinflammatory cytokines (e.g., interleukin [IL]-1 and IL-6) [14]; enhancement of leukocyte migration [19]; neutrophil and eosinophil activation [19,20]; induction of acute phase reactants and other liver proteins [14]; and induction of apoptosis in tissue cells [21]. This MOA is common to all TNF antagonists and is relevant to all indications for which infliximab is licensed in Europe and elsewhere. The TNF binding and neutralization activities of CT-P13 and infliximab RMP have been compared in vitro using ELISA and cell-based assays and shown to be equivalent [9]. 

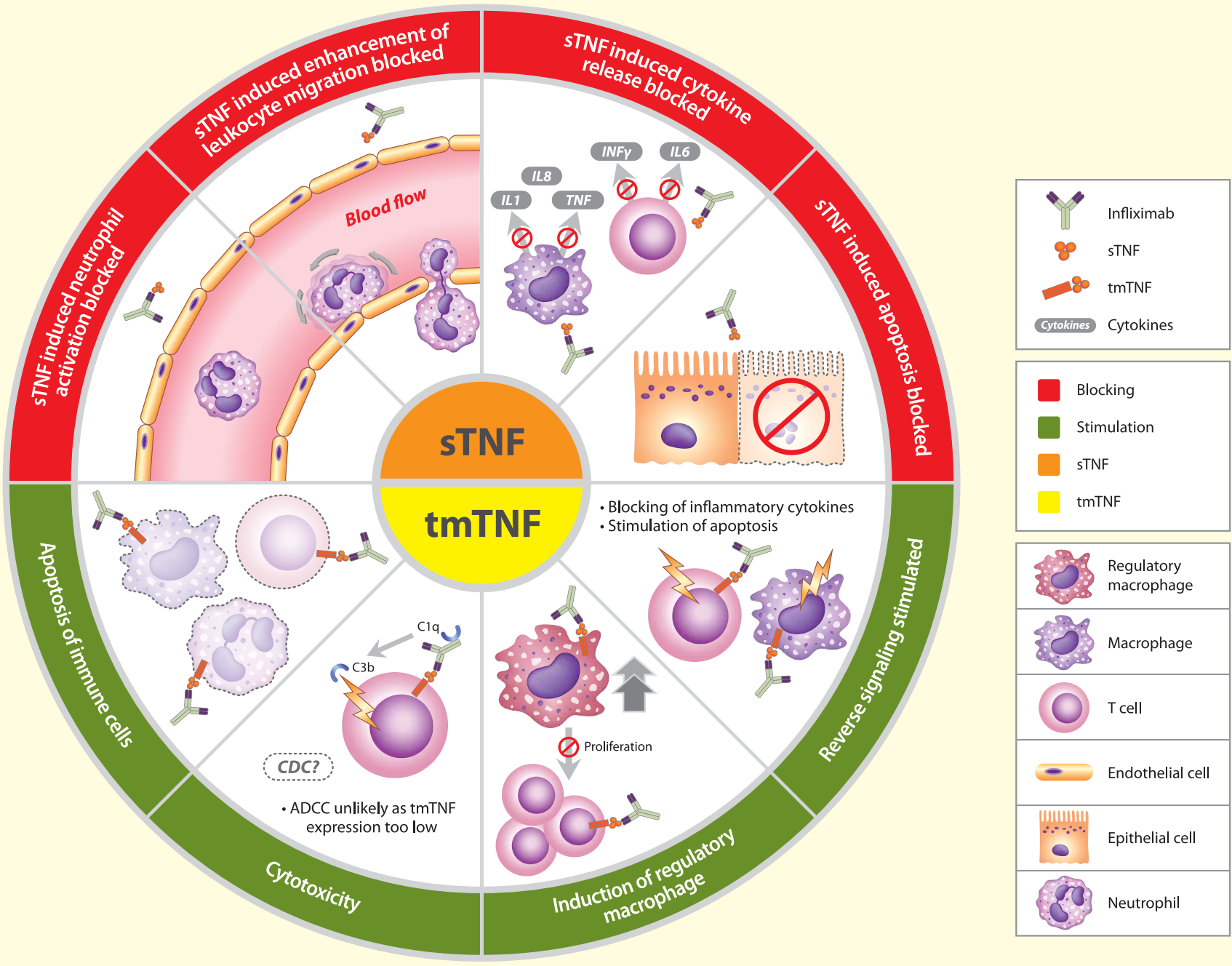

Figure 1. Diagrammatic representation of the mechanisms of action of infliximab. Binding of infliximab blocks the interaction of sTNF with TNFR1 and TNFR2 and prevents release of proinflammatory cytokines and apoptosis of the TNFR-bearing cell. This mechanism is common to all TNF antagonists and relevant to all indications for infliximab. Binding of infliximab to tmTNF blocks the forward signaling mechanisms but activates the reverse signaling pathways. Binding to tmTNF is considered particularly important in IBD because effects mediated through reverse signaling into tmTNF-bearing cells may include cytokine suppression, induction of apoptosis and induction of regulatory macrophages. Evidence from a range of TNF antagonists indicates that suppression of bacterially stimulated cytokine induction is also key for the therapeutic effect in IBD. The role for other mechanisms such as cytotoxicity is speculative and a matter of debate $[14,19,31,32,34,62]$.

ADCC: Antibody-dependent cellular cytotoxicity; CDC: Complement-dependent cytotoxicity; IBD: Inflammatory bowel disease; sTNF: Soluble tumor necrosis factor; tmTNF: Transmembrane tumor necrosis factor; TNFR: Tumor necrosis factor receptor.

\section{Induction of reverse signaling}

Signaling by tmTNF occurs not only by conventional ligand-receptor interactions but also via a process called reverse signaling. This process involves tmTNF acting as a receptor, in contrast to its usual role as a ligand. In this mode, the tmTNF sends signals back into tmTNF-expressing cells, which activate signaling pathways culminating in a number of downstream effects including apoptosis and cytokine suppression [14,22,23]. The existence of a role for reverse signaling in mediating a therapeutic response in IBD is supported by two related facts that: whereas infliximab and other $\mathrm{mAb}$ TNF antagonists are capable of inducing reverse signaling, etanercept is not; and whereas these mAbs are effective in IBD indications, etanercept had no such activity at the doses tested (perhaps suggesting that higher doses or more frequent dosing may be required in IBD) [24-26].

The extent of blockade of proinflammatory cytokine production by reverse signaling through tmTNF has been shown to be comparable for CT-P13 and RMP using peripheral blood mononuclear cells from healthy donors or patients with CD [8]. Furthermore, the reverse signaling-driven apoptotic effects of these two drugs have also been shown to be comparable in Jurkat cells stably transfected with tmTNF [8,9] In the latter assay, the average (range) activity of CT-P13 and RMP 
standardized as a percentage value was 101\% (91-105) and $101 \%$ (92-110), respectively ( $\mathrm{p}<0.0001$ for equivalence) [9].

\section{Regulatory macrophage induction \& wound healing}

Macrophages are involved in all phases of wound healing, including inflammation, the creation of granulation tissue, and matrix deposition [27]. Both proinflammatory 'M1' macrophages and anti-inflammatory or regulatory 'M2' macrophages exist and their relative distribution is thought to be important in the etiology of IBD. The lamina propria macrophages of patients with IBD are predominantly M1 [28,29]. It is known that the production of M1 macrophages is stimulated by exposure to TNF [30] and can therefore be inhibited by infliximab. Macrophage populations can be affected by TNF antagonists, which may play a role in the therapeutic response elicited in patients with IBD. Studies by Vos et al. have shown that infliximab and adalimumab, but not certolizumab, are able to decrease the proliferation capacity of activated $\mathrm{T}$ cells in the environment of a mixed lymphocyte reaction but not in assays using isolated T-cell populations [31]. The authors suggested that in order for infliximab to inhibit $\mathrm{T}$-cell proliferation in vitro, the antibody needs to bind to tmTNF on activated $\mathrm{T}$ cells and to possess an $\mathrm{Fc}_{\mathrm{C}}$ region that can interact with the Fc receptor on antigen-presenting cells, such as macrophages that are present in a mixed lymphocyte reaction environment. Upon binding, the production of a regulatory macrophage subset occurs which exhibits immunosuppressive capacities, including the production of anti-inflammatory cytokines and the inhibition of T-cell proliferation. Further studies in patients with IBD demonstrated that the numbers of regulatory macrophages increased in patients with IBD who responded to infliximab treatment with evidence of mucosal healing, but not in nonresponders [32]. This induction of regulatory macrophages and subsequent inhibition of T-cell proliferation appears to be an important MOA of infliximab in IBD.

The comparability of CT-P13 and infliximab RMP was investigated in mixed lymphocyte reaction assays using peripheral blood mononuclear cells from healthy and CD donors. To remove any confounding effect of FcyRIIIa receptor polymorphisms on the binding, genotype-matched peripheral blood mononuclear cells were used. No differences were detected between CT-P13 and RMP in the proportion of regulatory macrophages induced or in inhibition of T-cell proliferation [8].

\section{Cytotoxicity}

Monoclonal antibodies such as infliximab may, in theory, induce cytotoxicity against tmTNF-bearing cells via complement-dependent cytotoxicity (CDC) and/or ADCC. Although there is no evidence for a role of CDC in the effects of infliximab in vivo, the comparative ability of CT-P13 and the infliximab RMP to induce CDC has been investigated in Jurkat cells overexpressing tmTNF. No differences in the ability of CT-P13 and RMP to induce lysis of these cells via CDC were detected; average (range) activity of CT-P13 and RMP standardized as a percentage value was $102 \%$
(91-116) and 93\% (84-115), respectively ( $p=0.0011$ for equivalence) $[8,9]$.

ADCC is the immune defense mechanism whereby immune effector cells such as macrophages or NK cells bind to the Fc region of antibody-antigen complexes on the surface of target cells and promote target cell lysis. ADCC is primarily mediated through a set of closely related Fc receptors possessing both stimulatory and inhibitory activities, with FcyRIIIa being particularly important. Many published in vitro studies have reported that infliximab can induce ADCC, although it should be noted that all of these studies were performed using TNFoverexpressing cell lines as the target cells [33-35]. Differences in binding of about $10-20 \%$ between FcyRIIIa and CT-P13 or $\mathrm{RMP}$ in NK cells and the resulting ADCC activity were a key factor in the decision of Health Canada not to approve CTP13 in CD and UC [8,12]. However, binding of CT-P13 and RMP to NK cells was also performed in the presence of diluted $\mathrm{CD}$ patient serum, to mimic the in vivo environment. When serum was added, the difference between CT-P13 and RMP was abrogated [8]. Moreover, when lipopolysaccharide (LPS)stimulated human monocytes were used as the target cells and peripheral blood mononuclear cells as the effector cells, no observable ADCC was seen in response to infliximab $[8,36]$. Since LPS-stimulated human monocytes are considered representative of the target cells encountered in vivo, these results suggest that ADCC is not likely to play a significant role in mediating the therapeutic effects of infliximab. Furthermore, certolizumab, which does not show any ADCC activity in vitro due to a lack of a Fc region in the protein structure, is effective and licensed in the USA for reducing the signs and symptoms of CD, as well as for the treatment of RA, AS, PsA and PsO, suggesting that $\mathrm{ADCC}$ is not a key MOA in these diseases [35].

\section{Pharmacokinetics \& biodistribution of RMP \& CT-P13 in IBD \& non-IBD indications}

In clinical studies of the infliximab RMP, no major differences in pharmacokinetic $(\mathrm{PK})$ parameters were observed in patient subgroups defined by age, weight or gender. The RMP has a linear PK profile and overall PK properties of the RMP across all approved indications are comparable [37].

The equivalence of PK between CT-P13 and RMP was established in a Phase I study in patients with AS (PLANETAS) (Figure 2) [10]. The endpoints of the study were the steadystate area under the serum-concentration curve (AUC) and maximum serum concentration (Cmax). PK equivalence was shown when the $90 \%$ confidence intervals (CIs) for the ratios of both AUC and Cmax (CT-P13/RMP) fell within a predefined margin of 80-125\% (AUC: $104.5 \%$ [90\% CI: $94-$ 116\%]; Cmax: 101.5\% [90\% CI: 95-109\%]). Very close similarity between the PK of CT-P13 and RMP has also been shown in patients with RA and healthy volunteers [11,38,39].

Tissue biodistribution has not been fully elucidated for infliximab RMP. It is not known whether there are differences in clearance or volume of distribution in patients with marked impairment of hepatic or renal function, and biodistribution is 
mainly confined to the central vascular compartment [37,40]. Accelerated clearance of infliximab has been observed in patients with acute UC [41] and the presence of infliximab in the stools of patients with severe IBD has been reported [42]. This effect is hypothetically attributed to IgG loss by capillary leak, epithelial barrier disruption and immune cells (exudate) in the feces, which is part of a complex of protein-losing enteropathy. Due to their comparable structural and functional properties, this passive diffusion and shedding of RMP $\operatorname{IgG}$ and CT-P13 IgG through the leaky gut wall is expected to be similar.

The clearance of infliximab can be influenced by the presence of antidrug antibodies (ADAs), and concomitant use of immunomodulators [43]. Prior studies have established the benefits of the infliximab RMP in the treatment of different autoimmune diseases, with or without immunosuppression. Concomitant immunomodulatory therapies have been shown to reduce clearance of infliximab by suppressing ADA formation [44], but immunomodulators, including methotrexate (MTX), can also influence infliximab clearance by ADA-independent mechanisms [43]. Likewise, thiopurines, and particularly azathioprine, were shown to suppress $\mathrm{ADA}$ formation in $\mathrm{CD}$ and UC patients. In UC, the use of azathioprine and immunomodulatory therapies did not impact population PK of infliximab [45]. However, azathioprine showed a trend for reduced ADA rate from 19 to $3 \%$ in the UC patients in the SUCCESS trial [46]. In CD patients, addition of azathioprine appeared to reduce ADA incidence in the SONIC study [47] and in prospectively followed cohorts [48], and also reduce the clearance of infliximab [49]. Moreover, in CD patients, MTX use with infliximab tended to be associated with higher median infliximab levels and reduction in ADA rate in the COMMIT trial [50].

In clinical studies of CT-P13, the PK of this biosimilar was shown to be comparable with that of the RMP whether patients received background MTX (as in the Phase III PLANETRA study in RA) or not (as in the PLANETAS study and a single-dose study in healthy volunteers) $[10,11,38]$. Furthermore, the impact of steroids alone on the PK results in PLANETAS, and of steroids plus MTX on PK results in PLANETRA, was evaluated via subgroup analyses. These analyses showed that regardless of background immunosuppression, the PK of CTP13 and RMP were similar across all patient populations [8]. Therefore, it is anticipated that, due to the similarity of PK and immunogenicity exhibited by CT-P13 and RMP, outcomes following use of these two drugs will be comparable, regardless of whether they are administered as monotherapy or in combination with other immunomodulatory agents.
Biosimilarity has thus been demonstrated between CT-P13 and the RMP with respect to PK in three distinct populations, namely AS patients, RA patients and healthy volunteers. Therefore, based on the biosimilarity exercise, it seems scientifically justified to extrapolate PK profiles for CT-P13 across target populations and conditions of use.

\section{Clinical experience with CT-P13 in IBD}

CT-P13 is now available for clinical use in UC and CD in many countries; therefore, real-life efficacy and safety data in these indications can provide essential insights, although it should be noted that these observations are small and uncontrolled and that these data are neither requested nor essential for the demonstration of biosimilarity (TABLE 1).

CT-P13 has been available for use in patients with IBD in Korea since July 2012, and data are accumulating in the literature. Treatment of a small number of patients $(n=17)$ with $C D$ or UC in a single center has shown a clinical response to CT-P13 therapy in both indications with no serious or unexpected adverse events (AEs) reported [51]. Recent data from a Korean postmarketing study are summarized in full within this supplement [52]. While this study was not powered for evaluating efficacy, positive outcomes were observed in terms of clinical response. Additionally, to date, no unexpected treatment-related AEs have been observed in this study. A multicenter retrospective analysis of 59 patients with CD (32 and 27 TNF antagonistnaive or switched from infliximab RMP, respectively) and 51 patients with UC (42 and 9, respectively) was performed in Korea. In naïve patients with $\mathrm{CD}$, rates of clinical response and remission at week 30 were 95.5 and $77.3 \%$, respectively; in such patients with UC, these rates were 91.3 and $47.8 \%$, respectively, while the rate of mucosal healing at week 30 was $66.7 \%$. In those 


\section{Table 1. Summary of clinical experience with CT-P13 in IBD.}

\begin{tabular}{|c|c|c|c|c|}
\hline Country & Patient numbers & Efficacy & Safety & Ref. \\
\hline South Korea & $\begin{array}{l}173 \\
(C D=95, U C=78)\end{array}$ & $\begin{array}{l}\text { Response: } 79.5 \text { and } 72.2 \% \text { in } C D \text { and } U C \\
\text { at week } 30 \\
\text { Remission: } 59.0 \text { and } 37.0 \% \text { in } C D \text { and } U C \\
\text { at week } 30\end{array}$ & $\begin{array}{l}\text { No unexpected AEs, well } \\
\text { tolerated }\end{array}$ & {$[52]$} \\
\hline South Korea & $\begin{array}{l}110 \\
(C D=59, U C=51)\end{array}$ & $\begin{array}{l}\text { Naïve: response } 95.5 \text { and } 91.3 \% \text { in CD } \\
\text { and UC at week } 30 \text {; remission } 77.3 \text { and } \\
47.8 \% \text { in CD and UC at week } 30 \\
\text { Switch: the efficacy of CT-P13 was } \\
\text { maintained in } 92.6 \text { and } 66.7 \% \text { of CD and } \\
\text { UC patients, respectively }\end{array}$ & $\begin{array}{l}\text { AEs related to CT-P13 } \\
\text { occurred in } 11.8 \% \text { of UC } \\
\text { patients }\end{array}$ & [53] \\
\hline South Korea & $\begin{array}{l}17 \\
(C D=8, U C=9)\end{array}$ & $\begin{array}{l}\text { Response: Mayo/CDAl: } \sim 87.5 \% \text { at } \\
\text { week } 8 \text { in switch and naïve }\end{array}$ & $\begin{array}{l}\text { One UC patient } \\
\text { experienced arthralgia }\end{array}$ & {$[51]$} \\
\hline Hungary & $\begin{array}{l}90 \\
(C D=57, U C=33)\end{array}$ & $\begin{array}{l}\text { Significant decrease in CDAl and partial } \\
\text { Mayo score }\end{array}$ & Four allergic reactions & [54] \\
\hline Hungary & $\begin{array}{l}12 \\
(\mathrm{UC})\end{array}$ & $\begin{array}{l}\text { Mucosal healing: } 78 \% \text { after induction } \\
\text { therapy }\end{array}$ & Not reported & {$[55]$} \\
\hline Norway & $\begin{array}{l}78 \\
(C D=46, U C=32)\end{array}$ & $\begin{array}{l}\text { Remission: } 79 \text { and } 56 \% \text { in CD and UC at } \\
\text { week } 14\end{array}$ & $\begin{array}{l}\text { There were no } \\
\text { unexpected AEs reported }\end{array}$ & {$[63]$} \\
\hline Poland & $\begin{array}{l}32 \\
\text { (pediatric CD) }\end{array}$ & $\begin{array}{l}\text { Switch: pediatric CDAl: } 48 \text { (start of RMP) } \\
\rightarrow 8.5 \text { (at switch to CT-P13) } \\
\rightarrow 7.5 \text { (CT-P13 at week } 8 \text { ) }\end{array}$ & No unexpected AEs & {$[58]$} \\
\hline Poland & $\begin{array}{l}12 \\
\text { (pediatric CD) }\end{array}$ & $\begin{array}{l}\text { Pediatric CDAl: } 52.5 \\
\rightarrow 5 \text { after induction dose }\end{array}$ & $\begin{array}{l}\text { AEs were observed in } \\
2 / 12(17 \%) \text { pts }\end{array}$ & {$[56]$} \\
\hline Poland & $\begin{array}{l}6 \\
\text { (pediatric UC) }\end{array}$ & $\begin{array}{l}\text { Pediatric UCAI: } 47.5 \text { at initiation } \\
\rightarrow 28.3 \text { at week } 10\end{array}$ & Not reported & {$[57]$} \\
\hline Ireland & $\begin{array}{l}36 \\
(14 \text { for CT-P13, } \\
22 \text { for RMP) }\end{array}$ & \multicolumn{2}{|c|}{$\begin{array}{l}\text { Clinical efficacy results were not reported } \\
\text { Surgery: } 4 \text { and } 0 \text { in CT-P13 and RMP-treated patients, respectively } \\
\text { (in two cases, surgery was performed within } 2 \text { weeks and the remainder } \\
\text { within } 6 \text { weeks of initiating CT-P13) }\end{array}$} & [59] \\
\hline
\end{tabular}

patients who switched from RMP, a clinical response was maintained in $92.6 \%$ and $66.7 \%$ of $\mathrm{CD}$ and UC patients, respectively. AEs related to CT-P13 occurred in $11.8 \%$ of UC patients [53].

In Hungary, interim data from a prospective, nationwide, observational cohort study of the safety and efficacy of CT-P13 in $\mathrm{CD}$ and UC have demonstrated significant decreases from baseline in disease activity, as assessed by mean Crohn's Disease Activity Index (CDAI) and partial Mayo Clinic scores [54]. Another study has shown evidence of mucosal healing in patients with acute UC after treatment with CT-P13 [55]. Three recent reports from Poland have focused on experiences with CT-P13 in a small number of children with IBD. Significant decreases in Pediatric CDAI score and inflammatory markers were observed in 10 children with CD after CT-P13 administration [56], and in another study, four children with UC experienced a reduction in Pediatric UC Activity Index scores [57]. No change in disease activity was observed in children with CD who were switched from infliximab RMP to CT-P13 [58].
In Ireland, a higher rate of surgery in CT-P13-treated patients compared with RMP-treated patients was reported (4/14 and 0/22 for CT-P13 and RMP, respectively) [59]. Before treatment with CT-P13, two patients who had surgery had higher CRP levels than any RMP-treated patients. In two cases, surgery was performed within 2 weeks and the remainder within 6 weeks of initiating CT-P13. Although this is the first case of comparative data between CT-P13 and RMP in patients with IBD, there are limitations to the study with regard to differences in patient disposition and baseline characteristics before treatment and efficacy assessments used.

As an overall summary, CT-P13 has been shown to be effective in approximately 518 patients with IBD; differences between CT-P13 and RMP have been reported from the comparison of 14 patients treated with CT-P13 and 22 patients treated with RMP in Ireland. Taken together, data from studies that have evaluated the use of CT-P13 in patients with IBD suggest that this biosimilar is effective and generally well tolerated. However, further data are welcome, and additional studies 
that will support the validity of indication extrapolation to IBD are ongoing. A randomized parallel-group Phase III study is underway that will assess the noninferiority in efficacy of CT-P13 compared with infliximab RMP, as well as treatment safety, in adults with CD [60]. Data for the primary endpoint of this study (CDAI 70 response at week 54 of treatment) are expected to be available in early 2016. A global registry study in IBD has also been initiated [61]. The study is recruiting adults or children aged $\geq 6$ years with active $C D$ and adults with fistulizing CD or UC. The primary objective of the study is to monitor the safety of CT-P13 in IBD patients; efficacy and health economic parameters will also be assessed.

\section{Conclusions}

In the current context, the term 'extrapolation' refers to the process of extending and applying data from clinical studies obtained in one medical condition or indication to another medical condition or indication. If biosimilarity to an RMP has been shown in a comprehensive comparability analysis including safety, efficacy and immunogenicity in a key indication that is suitable to detect potentially relevant differences then based on current guidelines, extrapolation may be permissible. Indeed, and although scientific questions have been raised regarding the validity of this approach with respect to biosimilars, regulatory agencies have provided detailed guidance on the scientific principles that must be followed in order for extrapolation to be valid. This includes extensive assessments of quality and biologic activity with results falling within the range observed for the RMP. In addition, comparable clinical efficacy and safety must be shown in a sensitive patient population. Only once this has been established will approval and extrapolation be considered. In the case of CT-P13, evidence from preclinical MOA studies and clinical PK studies appears to support the use of this biosimilar in IBD. Evidence emerging from studies involving 'real-life' use of CT-P13 in patients with CD and UC is in line with the conclusion that this biosimilar is effective and well tolerated in these populations. Further data on the use of CT-P13 in IBD are eagerly awaited, particularly in situations where available data with the RMP are missing, to help optimize the use of infliximab in IBD.

\section{Expert commentary}

Extrapolation of clinical data to cover a range of approved indications is not a new concept within the field of biologics. Stringent guidelines are in place to show comparability between a biologic and a biosimilar both in vitro and in the clinic. However, discussion of the validity of this approach to regulatory licensing persists. In this article, we have used the approval of CT-P13 for all indications held by RMP infliximab, as a case study to highlight how a thorough understanding of the MOAs of the drug and interpretation of data accumulated during the development process can be used to support extrapolation. Emerging results from the clinic for CT-P13 in IBD are encouraging, and additional studies are planned. The scientific basis of the extrapolation process is valid for biosimilars but should be applied on a case-by-case basis after careful scrutiny of all available data.

\section{Five-year view}

A patent cliff for biologics is looming and so the development and approval of biosimilars is set to rise over the next few years. As the market grows and healthcare professionals become more acquainted with biosimilars, the idea and validity of extrapolation will become more mainstream and questions relating to this approach to regulatory approval of indications should be answered. However, strict guidelines and postapproval pharmacovigilance must be maintained to ensure patient safety. The further development of biosimilars will enhance the treatment options available to patients and the extrapolation of data will allow the benefits of these new agents to reach as many patients as possible.

\section{Financial \& competing interests disclosure}

W Reinisch has served as a speaker for Abbott Laboratories, Abbvie, Aesca, Aptalis, Centocor, Celltrion, Danone Austria, Elan, Falk Pharma GmbH, Ferring, Immundiagnostik, Mitsubishi Tanabe Pharma Corp, MSD, Otsuka, PDL, Pharmacosmos, Schering-Plough, Shire, Takeda, Therakos, Vifor, Yakult; as a consultant for Abbott Laboratories, Abbvie, Aesca, Amgen, AM Pharma, Astellas, Astra Zeneca, Avaxia, Bioclinica, Biogen IDEC, Bristol-Myers Squibb, Cellerix, Chemocentryx, Celgene, Centocor, Celltrion, Covance, Danone Austria, Elan, Falk Pharma GmbH, Ferring, Galapagos, Genentech, Gilead, Grunenthal, ICON, Index Pharma, Inova, Janssen, Johnson \& Johnson, Kyowa Hakko Kirin Pharma, Lipid Therapeutics, MedImmune, Millenium, Mitsubishi Tanabe Pharma Corp, MSD, Nestle, Novartis, Ocera, Otsuka, PDL, Pharmacosmos, Pfizer, Procter \& Gamble, Prometheus, Robarts Clinical Trial, Schering-Plough, Second Genome, Setpointmedical, Takeda, Therakos, Tigenix, UCB, Vifor, Zyngenia, and 4SC; as an advisory board member for Abbott Laboratories, Abbvie, Aesca, Amgen, AM Pharma, Astellas, Astra Zeneca, Avaxia, Biogen IDEC, Bristol-Myers Squibb, Cellerix, Chemocentryx, Celgene, Centocor, Celltrion, Danone Austria, Elan, Ferring, Galapagos, Genentech, Grunenthal, Inova, Janssen, Johnson \& Johnson, Kyowa Hakko Kirin Pharma, Lipid Therapeutics, MedImmune, Millenium, Mitsubishi Tanabe Pharma Corp, MSD, Nestle, Novartis, Ocera, Otsuka, PDL, Pharmacosmos, Pfizer, Procter \& Gamble, Prometheus, ScheringPlough, Second Genome, Setpointmedical, Takeda, Therakos, Tigenix, $U C B$, Zyngenia, and $4 S C$, and has received research funding from Abbott Laboratories, Abbvie, Aesca, Centocor, Falk Pharma GmbH, Immundiagnostik and MSD. E. Louis has received educational grants from MSD and Abbvie, and speaker fees from Abbvie, Ferring, MSD, Chiesi, Mitsubishi Pharma, Hospira, and Janssen. He has also served as an advisory board member for Abbvie, Ferring, MSD, Takeda, Mitsubishi Pharma, and Celltrion. S. Danese has served as a speaker, a consultant and an advisory board member for Schering-Plough, Abbott Laboratories, Abbvie, Merck \& Co, UCB Pharma, Ferring, Cellerix, Celltrion, Millenium Takeda, Nycomed, Pharmacosmos, Actelion, Alfa wassermann, Genentech, Grunenthal, Pfizer, Astra Zeneca, Novo Nordisk, Cosmo Pharmaceuticals, Pharmacosmos, Tigenix, Vifor, and Johnson and Johnson. The authors have no other relevant affiliations or financial involvement with any organization or entity with a financial interest in or financial conflict with 
the subject matter or materials discussed in the manuscript apart from those disclosed. Editorial support (writing assistance, assembling tables and figures, collating author comments, grammatical editing, and referencing) was provided by Rick Flemming (Aspire Scientific Limited, Bollington, UK) and was funded by Celltrion Healthcare Co., Ltd (Incheon, Republic of Korea).

\section{Key issues}

- The EMA approved CT-P13 for all indications held by the infliximab RMP based on evidence from a comprehensive comparability program that demonstrated equivalence in efficacy, safety and pharmacokinetics.

- The extrapolation of clinical data is fundamental to the development of biosimilars, but its use in the approval process is still subject to some debate.

- The overexpression of TNF is a common feature of many immune-mediated inflammatory diseases, and the efficacy of TNF antagonists is well established.

- The role of TNF in the pathogenesis of inflammatory bowel disease (IBD) is varied, but infliximab has been shown to affect key mechanisms of action including reverse signaling and regulatory macrophage induction. The similarity in this regard between CT-P13 and infliximab reference medicinal product suggests that CT-P13 has comparable effects with infliximab RMP in patients with IBD.

- Emerging real-life efficacy and safety data from patients with IBD treated with CT-P13 support the extrapolation of data to include IBD indications for CT-P13.

- The extrapolation of clinical data as part of the biosimilar approval process is valid, but requires stringent analysis on a case-by-case basis. Strict postapproval pharmacovigilance is necessary.

\section{References}

Papers of special note have been highlighted as:

- of interest

- of considerable interest

1. Weise M, Kurki P, Wolff-Holz E, et al. Biosimilars: the science of extrapolation. Blood 2014;124:3191-6

2. European Medicines Agency. Guideline on similar biological medicinal products containing biotechnology-derived proteins as active substance: non-clinical and clinical issues. 2015. Available from: www.ema. europa.eu/docs/en_GB/document_library/ Scientific_guideline/2015/01/ WC500180219.pdf [Last accessed 28 April 2015]

3. Ebbers HC. Biosimilars: in support of extrapolation of indications. J Crohns Colitis 2014;8:431-5

4. Feagan BG, Choquette D, Ghosh S, et al. The challenge of indication extrapolation for infliximab biosimilars. Biologicals 2014;42: 177-83

- A review highlighting the process of indication extrapolation for biosimilars of infliximab.

5. Lee H. Is extrapolation of the safety and efficacy data in one indication to another appropriate for biosimilars? AAPS J 2014;16:22-6

6. European Medicines Agency. Remicade (infliximab). Summary of product Characteristics. 2014. Available from: www. ema.europa.eu/docs/en_GB/ document_library/EPAR_-
Product_Information/human/000240/ WC500050888.pdf [Last accessed 28 April 2015]

7. European Medicines Agency. Remsima (infliximab). Summary of product characteristics. 2014. Available from: www. ema.europa.eu/docs/en_GB/document_ library/EPAR___Product_Information/ human/002576/WC500150871.pdf [Last accessed 28 April 2015]

8. European Medicines Agency. Committee for medicinal products for human use (CHMP). Assessment report: Remsima (infliximab). 2013. Available from: www.ema.europa.eu/ docs/en_GB/document_library/EPAR_-_ Public_assessment_report/human/002576/ WC500151486.pdf [Last accessed 28 April 2015]

9. Jung SK, Lee KH, Jeon JW, et al. Physicochemical characterization of Remsima. MAbs 2014;6:1163-77

- Article presenting basic science for the comparable physicochemical properties of CT-P13 (Remsima ${ }^{\circledR} /$ Inflectra ${ }^{\circledR}$ ) and infliximab (Remicade $\left.{ }^{\circledR}\right)$.

10. Park W, Hrycaj P, Jeka $S$, et al. A randomised, double-blind, multicentre, parallel-group, prospective study comparing the pharmacokinetics, safety, and efficacy of CT-P13 and innovator infliximab in patients with ankylosing spondylitis: the PLANETAS study. Ann Rheum Dis 2013;72:1605-12

- $\quad$ Randomized controlled study highlighting the comparable pharmacokinetic, efficacy and safety profiles of CT-P13 and infliximab in patients with AS.

11. Yoo DH, Hrycaj P, Miranda P, et al. A randomised, double-blind, parallel-group study to demonstrate equivalence in efficacy and safety of CT-P13 compared with innovator infliximab when coadministered with methotrexate in patients with active rheumatoid arthritis: the PLANETRA study. Ann Rheum Dis 2013;72:1613-20

-• Randomized controlled study highlighting the comparable efficacy and safety profiles of CT-P13 and infliximab in patients with RA.

12. Health Canada. Summary basis of decision (SBD) for Remsima. 2014. Available from: www.hc-sc.gc.ca/dhp-mps/prodpharma/sbdsmd/drug-med/ sbd_smd_2014_remsima_160195-eng.php [Last accessed 28 April 2015]

13. Blandizzi C, Gionchetti P, Armuzzi A, et al. The role of tumour necrosis factor in the pathogenesis of immune-mediated diseases. Int J Immunopathol Pharmacol 2014;27: $1-10$

14. Tracey D, Klareskog L, Sasso EH, et al. Tumor necrosis factor antagonist mechanisms of action: a comprehensive review. Pharmacol Ther 2008;117:244-79

15. Reinecker HC, Steffen M, Witthoeft T, et al. Enhanced secretion of tumour necrosis factor-alpha, IL-6, and IL-1 beta by isolated lamina propria mononuclear cells from patients with ulcerative colitis and Crohn's disease. Clin Exp Immunol 1993;94:174-81 
16. Breese EJ, Michie CA, Nicholls SW, et al. Tumor necrosis factor alpha-producing cells in the intestinal mucosa of children with inflammatory bowel disease. Gastroenterology 1994;106:1455-66

17. Nicholls S, Stephens S, Braegger CP, et al. Cytokines in stools of children with inflammatory bowel disease or infective diarrhoea. J Clin Pathol 1993;46:757-60

18. Armuzzi A, Lionetti P, Blandizzi $\mathrm{C}$, et al. anti-TNF agents as therapeutic choice in immune-mediated inflammatory diseases: focus on adalimumab. Int J Immunopathol Pharmacol 2014;27:11-32

19. Van Deventer SJ. Tumour necrosis factor and Crohn's disease. Gut 1997;40:443-8

20. Kankaanranta H, Ilmarinen P, Zhang X, et al. Tumour necrosis factor-alpha regulates human eosinophil apoptosis via ligation of TNF-receptor 1 and balance between NF-kappaB and AP-1. PLoS One 2014;9: e90298

21. Goretsky T, Dirisina R, Sinh P, et al. p53 mediates TNF-induced epithelial cell apoptosis in IBD. Am J Pathol 2012;181: 1306-15

22. Eissner G, Kirchner S, Lindner H, et al. Reverse signaling through transmembrane TNF confers resistance to lipopolysaccharide in human monocytes and macrophages. J Immunol 2000;164:6193-8

23. Oikonomopoulos A, van Deen WK, Hommes DW. Anti-TNF antibodies in inflammatory bowel disease: do we finally know how it works? Curr Drug Targets 2013;14:1421-32

24. Mitoma $\mathrm{H}$, Horiuchi $\mathrm{T}$, Hatta $\mathrm{N}$, et al. Infliximab induces potent anti-inflammatory responses by outside-to-inside signals through transmembrane TNF-alpha. Gastroenterology 2005;128:376-92

25. Sandborn WJ, Hanauer SB, Katz S, et al. Etanercept for active Crohn's disease: a randomized, double-blind, placebo-controlled trial. Gastroenterology 2001;121:1088-94

26. Sedger LM, McDermott MF. TNF and TNF-receptors: From mediators of cell death and inflammation to therapeutic giants - past, present and future. Cytokine Growth Factor Rev 2014;25:453-72

27. Sindrilaru A, Scharffetter-Kochanek K. Disclosure of the culprits: macrophages-versatile regulators of wound healing. Adv Wound Care (New Rochelle) 2013;2:357-68

28. Zareie M, Singh PK, Irvine EJ, et al. Monocyte/macrophage activation by normal bacteria and bacterial products: implications for altered epithelial function in Crohn's disease. Am J Pathol 2001;158:1101-9

29. Zhu W, Yu J, Nie Y, et al. Disequilibrium of M1 and M2 macrophages correlates with the development of experimental inflammatory bowel diseases. Immunol Invest 2014;43:638-52

30. Wang N, Liang H, Zen K. Molecular mechanisms that influence the macrophage m1-m2 polarization balance. Front Immunol 2014;5:614

31. Vos AC, Wildenberg ME, Duijvestein M, et al. Anti-tumor necrosis factor-alpha antibodies induce regulatory macrophages in an $F_{c}$ region-dependent manner. Gastroenterology 2011;140:221-30

32. Vos AC, Wildenberg ME, Arijs I, et al. Regulatory macrophages induced by infliximab are involved in healing in vivo and in vitro. Inflamm Bowel Dis 2012;18: 401-8

- Study highlighting the induction of regulatory macrophages by infliximab and their potential role in mucosal healing.

33. Arora T, Padaki R, Liu L, et al. Differences in binding and effector functions between classes of TNF antagonists. Cytokine 2009;45:124-31

34. Mitoma H, Horiuchi T, Tsukamoto H, et al. Mechanisms for cytotoxic effects of anti-tumor necrosis factor agents on transmembrane tumor necrosis factor alpha-expressing cells: comparison among infliximab, etanercept, and adalimumab. Arthritis Rheum 2008;58:1248-57

- Study highlighting the role of infliximab in the induction of reverse signaling and inhibition of the inflammatory response.

35. Nesbitt A, Fossati G, Bergin M, et al. Mechanism of action of certolizumab pegol (CDP870): in vitro comparison with other anti-tumor necrosis factor alpha agents. Inflamm Bowel Dis 2007;13:1323-32

36. Shealy DJ, Cai A, Staquet K, et al. Characterization of golimumab, a human monoclonal antibody specific for human tumor necrosis factor alpha. MAbs 2010;2: 428-39

37. Remicade US Prescribing Information. 2013. Available from: www.remicade.com/ shared/product/remicade/prescribinginformation.pdf [Last accessed 30 April 2015]

38. Yoo D-H, Park W, Shim S-C, et al. A randomized, double-blind, three-arm, parallel group, single-dose study to compare the pharmacokinetics, safety, and tolerability of three formulations of infliximab (CT-
P13, EU-sourced infliximab and US-sourced infliximab) in healthy volunteers. Arthritis Rheumatol 2014;11(Suppl):S664; 1509

39. Takeuchi T, Yamanaka H, Tanaka Y, et al. Evaluation of the pharmacokinetic equivalence and 54-week efficacy and safety of CT-P13 and innovator infliximab in Japanese patients with rheumatoid arthritis. Mod Rheumatol 2015;1-8

40. Schwab M, Klotz U. Pharmacokinetic considerations in the treatment of inflammatory bowel disease. Clin Pharmacokinet 2001;40:723-51

41. Kevans D, Murthy S, Iacono A, et al. Accelerated clearance of serum infliximab during induction therapy for acute ulcerative colitis is associated with treatment failure. Gastroenterology 2012;142(Suppl 5):S384-5; Sa2031

42. Brandse JF, Wildenberg ME, de Bruyn JR, et al. Fecal loss of infliximab as a cause of lack of response in severe inflammatory bowel disease. J Crohns Colitis 2013;7:S210

43. Yarur AJ, Abreu MT, Deshpande AR, et al. Therapeutic drug monitoring in patients with inflammatory bowel disease. World J Gastroenterol 2014;20:3475-84

44. Krieckaert CL, Bartelds GM, Lems WF, et al. The effect of immunomodulators on the immunogenicity of TNF-blocking therapeutic monoclonal antibodies: a review. Arthritis Res Ther 2010;12:217

45. Fasanmade AA, Adedokun OJ, Ford J, et al. Population pharmacokinetic analysis of infliximab in patients with ulcerative colitis. Eur J Clin Pharmacol 2009;65:1211-28

46. Panaccione R, Ghosh S, Middleton S, et al. Combination therapy with infliximab and azathioprine is superior to monotherapy with either agent in ulcerative colitis. Gastroenterology 2014;146:392-400 e3

47. Colombel JF, Sandborn WJ, Reinisch W, et al. Infliximab, azathioprine, or combination therapy for Crohn's disease. N Engl J Med 2010;362:1383-95

48. Ungar B, Chowers Y, Yavzori M, et al. The temporal evolution of antidrug antibodies in patients with inflammatory bowel disease treated with infliximab. Gut 2014;63: 1258-64

49. Fasanmade AA, Adedokun OJ, Blank M, et al. Pharmacokinetic properties of infliximab in children and adults with Crohn's disease: a retrospective analysis of data from 2 phase III clinical trials. Clin Ther 2011;33:946-64

50. Feagan BG, McDonald JW, Panaccione R, et al. Methotrexate in combination with infliximab is no more effective than 
infliximab alone in patients with Crohn's disease. Gastroenterology 2014;146: 681-688 e1

51. Kang YS, Moon HH, Lee SE, et al. Clinical experience of the use of CT-P13, a biosimilar to infliximab in patients with inflammatory bowel disease: A case series. Dig Dis Sci 2015;60:951-6

52. Park SH, Kim YH, Lee JU, et al. Postmarketing study of biosimilar infliximab to evaluate its safety and efficacy in Korea. Expert Rev Gastroenterol Hepatol 2015. [Epub ahead of print]

53. Jung YS, Park DI, Kim YH, et al. Efficacy and safety of CT-P13, a biosimilar of infliximab, in patients with inflammatory bowel disease: A retrospective multicenter study. J Gastroenterol Hepatol 2015. [Epub ahead of print]

54. Gecse K, Farkas K, Lovasz B, et al. Biosimilar infliximab in inflammatory bowel diseases: first interim results from a prospective nationwide observational cohort J Crohns Colitis. 2015;9(Suppl 1):S234-5; P314
55. Molnar T, Farkas K, Rutka M, et al. Efficacy of the new infliximab biomarker CT-P13 induction therapy on mucosal healing in ulcerative colitis patients. J Crohns Colitis 2015;9(Suppl 1):S382; P603

56. Sieczkowska J, Banaszkiewicz A, Plocek A, et al. Assessment of safety and efficacy of biosimilar infliximab in children with Crohn disease: a preliminary report. J Crohns Colitis 2015;9(Suppl 1):S295; $\mathrm{P} 430$

57. Jarzebicka D, Plocek A, Sieczkowska J, et al. First observations of the use of biosimilar infliximab for treatment of ulcerative colitis in paediatric population. J Crohns Colitis 2015;9(Suppl 1):S307-8; P456

58. Jarzebicka D, Banaszkiewicz A, Plocek A, et al. Preliminary assessment of efficacy and safety of switching between originator and biosimilar infliximab in paediatric Crohn disease patients. J Crohns Colitis 2015; 9(Suppl 1):S224-5; P295
59. Murphy C, Sugrue K, Mohamed G, et al. Biosimilar but not the same. J Crohns Colitis 2015;9(Suppl 1):S331-2; P505

60. Demonstrate noninferiority in efficacy and to assess safety of CT-P13 in patients with active Crohn's disease. Available from: https:/clinicaltrials.gov/ct2/show/ NCT02096861

61. To evaluate the safety and efficacy of Remsima $^{\mathrm{TM}}$ in patients with Crohn's disease (CD) or ulcerative colitis (UC). Available from: https://clinicaltrials.gov/ct2/show/ NCT02326155

62. Bosani M, Ardizzone S, Porro GB. Biologic targeting in the treatment of inflammatory bowel diseases. Biologics 2009;3:77-97

63. Jahnsen J, Detlie TE, Vatn S, Ricanek P Biosimilar infliximab (CT-P13) in the treatment of inflammatory bowel disease: a Norwegian observational study. Expert Rev Gastroenterol Hepatol 2015. [Epub ahead of print] 